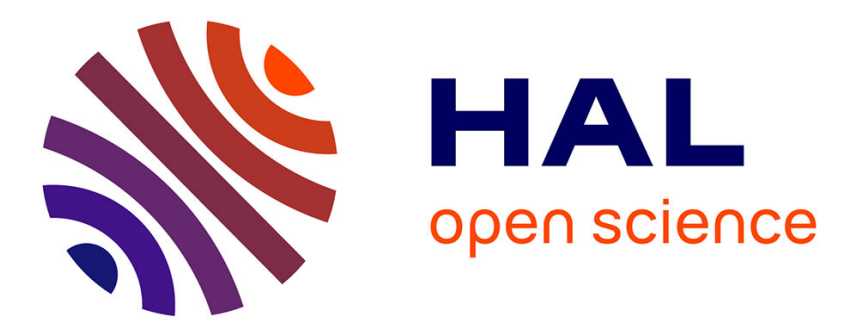

\title{
Cationic microbubbles and antibiotic-free miniplasmid for sustained ultrasound-mediated transgene expression in liver
}

Simona Manta, Gilles Renault, Anthony Delalande, Olivier Couture, Isabelle Lagoutte, Johanne Seguin, Franck Lager, Pascal Houzé, Patrick Midoux, Michel Bessodes, et al.

\section{To cite this version:}

Simona Manta, Gilles Renault, Anthony Delalande, Olivier Couture, Isabelle Lagoutte, et al.. Cationic microbubbles and antibiotic-free miniplasmid for sustained ultrasound-mediated transgene expression in liver. Journal of Controlled Release, 2017, 262, pp.170 - 181. 10.1016/j.jconrel.2017.07.015 . hal01656574

\section{HAL Id: hal-01656574 https://hal.science/hal-01656574}

Submitted on 21 Jan 2018

HAL is a multi-disciplinary open access archive for the deposit and dissemination of scientific research documents, whether they are published or not. The documents may come from teaching and research institutions in France or abroad, or from public or private research centers.
L'archive ouverte pluridisciplinaire HAL, est destinée au dépôt et à la diffusion de documents scientifiques de niveau recherche, publiés ou non, émanant des établissements d'enseignement et de recherche français ou étrangers, des laboratoires publics ou privés. 
Cationic Microbubbles and Antibiotic-free miniplasmid for sustained Ultrasound-mediated Transgene Expression in Liver

Simona Manta ${ }^{\mathrm{a}}$, Gilles Renault ${ }^{\mathrm{b}}$, Anthony Delalande ${ }^{\mathrm{c}}$, Olivier Couture ${ }^{\mathrm{d}}$, Isabelle Lagoutte ${ }^{\mathrm{b}}$, Johanne Seguin ${ }^{\mathrm{a}}$, Franck Lager ${ }^{\mathrm{b}}$, Pascal Houzéa ${ }^{\mathrm{a}}$ Patrick Midoux ${ }^{\mathrm{c}}$, Michel Bessodes ${ }^{\mathrm{a}}$, Daniel Scherman ${ }^{\mathrm{a}}$, Michel-Francis Bureau ${ }^{\mathrm{a}}$, Corinne Marie ${ }^{\mathrm{a}}$, Chantal Pichon ${ }^{\mathrm{c}} \S$, Nathalie Mignet $^{\mathrm{a} \S}$

${ }^{a}$ CNRS, UTCBS UMR 8258, F-75006 Paris, France; Université Paris Descartes, Sorbonne-ParisCité, UTCBS, F-75006 Paris, France; Chimie ParisTech, PSL Research University, Unité de Technologies Chimiques et Biologiques pour la Santé (UTCBS), F-75005 Paris, France; INSERM, UTCBS U 1022, F-75006 Paris, France

b INSERM, U1016, Institut Cochin, Paris, France; CNRS, UMR8104, Paris, France; Université Paris Descartes, Sorbonne Paris Cité, France.

${ }^{\mathrm{c}}$ Centre de Biophysique Moléculaire, UPR 4301, F-45071 Orléans, France.

d Institut Langevin - Ondes et Images; ESPCI ParisTech, PSL Research University, CNRS UMR7587, INSERM U979 ; 1, rue Jussieu, 75238 PARIS CEDEX 05, France

\section{* Corresponding author:}

Chantal Pichon: e-mail address Chantal.PICHON@cnrs.fr; Centre de Biophysique Moléculaire, UPR 4301, F-45071 Orléans, France.

${ }^{\S}$ C.P and N.M have contributed equally to this work. 


\begin{abstract}
Despite the increasing number of clinical trials in gene therapy, no ideal methods still allow non viral gene transfer in deep tissues such as the liver. We were interested in ultrasound (US)-mediated gene delivery to provide long term liver expression. For this purpose, new positively charged microbubbles were designed and complexed with pFAR4, a highly efficient small length miniplasmid DNA devoid of antibiotic resistance sequence. Sonoporation parameters, such as insonation time, acoustic pressure and duration of plasmid injection were controlled under ultrasound imaging guidance. The optimization of these various parameters was performed by bioluminescence optical imaging of luciferase reporter gene expression in the liver. Mice were injected with $50 \mu \mathrm{g}$ pAR4LUC either alone, or complexed with positively charged microbubbles, or co-injected with neutral MicroMarkerTM microbubbles, followed by low ultrasound energy application to the liver. Injection of the pFAR4 encoding luciferase alone led to a transient transgene expression that lasted only for two days. The significant luciferase signal obtained with neutral microbubbles decreased over 2 days and reached a plateau with a level around 1 log above the signal obtained with pFAR4 alone. With the newly designed positively charged microbubbles, we obtained a much stronger bioluminescence signal which increased over 2 days. The 12 -fold difference $(\mathrm{p}<0.05)$ between MicroMarker ${ }^{\mathrm{TM}}$ and our positively charged microbubbles was maintained over a period of 6 months. Noteworthy, the positively charged microbubbles led to an improvement of 180 -fold $(\mathrm{p}<0.001)$ as regard to free pDNA using unfocused ultrasound performed at clinically tolerated ultrasound amplitude. Transient liver damage was observed when using the cationic microbubble-pFAR4 complexes and the optimised sonoporation parameters. Immunohistochemistry analyses were performed to determine the nature of cells transfected. The pFAR4 miniplasmid complexed with cationic microbubbles allowed to transfect mostly hepatocytes compared to its co-injection with MicroMarker ${ }^{\mathrm{TM}}$ which transfected more preferentially endothelial cells.
\end{abstract}

Keywords: Cationic microbubbles; Ultrasound imaging; Physical delivery; Liver gene delivery; Image-guided delivery, transfection, miniplasmid. 


\section{Introduction}

Due to its fundamental role in metabolism, liver has attracted a number of therapeutic strategies, in particular gene therapy [1]. Various technologies have been applied such as viral or non-viral gene delivery associated or not with physical methods, such as hydrodynamic or ultrasound mediated gene delivery [2]. In terms of physical methods, ultrasound (US) advantageously allows to non-invasively reach deep tissues, and therefore shows great interest in gene delivery $[3,4]$.

Various studies have reported the efficacy of ultrasound-mediated microbubbles (MB) gene delivery. The majority of the studies were obtained with therapeutic ultrasound operating at frequency between 1 to $3 \mathrm{MHz}$ and various types of $\mathrm{MB}$, made with gaseous liposomes or polymers $[5,6]$. In this context, with microbubbles constituted of liposomal nanobubbles, the group of Tanyama has described an efficient IL12 gene expression within tumours [5]. Long lasting gene expression (up to 100 days) was obtained following co-injection of plasmid DNA encoding luciferase gene (pDNALUC) and MicroMarker ${ }^{\mathrm{TM}} \mathrm{MB}$ either in tendons [7] or in the muscle [8]. In the liver, two main studies have been published. The first study used the Optison ${ }^{\mathrm{TM}}$ ultrasound contrast agent which was co-injected with pDNA directly inside mice liver followed by ultrasound exposure [9]. The second study used a zwitterionic MB (a mix of DL- $\alpha$-phosphatidylcholine, dipalmitolyl and DL- $\alpha$ phosphatidylethanolamine, dipalmitolyl) loaded with pDNA injected into the left ventricle of the heart, followed by an ultrasound application in the liver area [10]. Significant expression of reporter genes such as green fluorescent protein, luciferase, beta-galactosidase, or therapeutic genes such as factor IX were observed in those two studies. The co-injection of Definity® MB with pDNA into a rat liver lobe via a specific portal vein branch promoted as well an increased gene transfection using high intensity ultrasound $(1.1 \mathrm{MHz}$ frequency, 20 cycles, $13.9 \mathrm{~Hz}$ of Pulse Repetition FrequencyPRF-, 2.7 MPa peak negative acoustic pressure) [11].

It is clear pDNA complexation with MB could be of interest for systemic delivery as it would allow both $\mathrm{MB}$ and pDNA to reach the targeted tissue at the same time. In addition, this complexation could reduce plasmid degradation, and thereby improving gene transfer.

Several strategies have been proposed to anchor nucleic acids at a microbubble surface. Some groups have exploited avidin-biotin linkage to couple nucleic acids complexed with cationic vectors (liposomes or polymers) on microbubble surface [12,13]. Various reports have described the use of cationic liposomes-based microbubbles [10,14-19], formed with gas-filled cationic liposomes made with zwitterionic lipid (DSPC) or cationic lipids such as DSTP or 1,2-stearoyl-3- 
trimethylammonium-propane (DPTAP). The main challenge is to obtain cationic MB promoting pDNA complexation without any alteration of their acoustic properties.

In addition to the improvement of physical gene delivery techniques, a particular attention was paid on plasmid design in the present study, which was identified to be of crucial importance. Indeed, in liver, non-viral gene vectors mostly display much more transient gene expression than that observed in other organs such as muscle, partly due to heterochromatin formation [20,21]. Removal of all or part of bacterial sequences from gene vectors (e.g. in minicircles or in pFAR4 miniplasmids, respectively) allowed to alleviate this silencing effect [22,23]. Alternatively, the use of molecular tools (DNA transposons or integrases) that mediate transgene integration into host genome led, in mice, to high and prolonged therapeutic levels of Factor IX that is deficient in hemophilia B patients. DNA transposon was also used to obtain gene insertion and long-term expression in combination with ultrasound using a low frequency unfocused transducer [11]. The use of unfocused transducer is of importance because it allows to treat a larger area, as compared to focused ultrasound, and is thus more appropriate for a large organ such as the liver.

Taking into account all these data, we ought to design positively charged MB to increase plasmid amount reaching the liver. Based on our former screening of positively charged lipids [24], we chose a highly charged bicatenar lipid with a branched polyspermine head [25]. We designed MB composed of a unique cationic lipid, providing a simple and reliable vector [26] able to interact with high efficiency with DNA. The other originality of our study comes from the pDNA used. We chose a miniplasmid devoid of antibiotic resistance sequence, called pFAR4 [27]. The absence of this sequence leads to a small size plasmid which was shown to be highly efficient in transfecting cells in vitro [27] and in vivo [23]. Finally, the parameters of low-energy unfocused ultrasound were also optimized using image-guided delivery. In this article, we report that the combination of plasmid molecular optimization and US non-invasive physical trigger led to a stable gene expression in the liver over 6 months, with a mild and transient apparent toxicity.

\section{Material and Methods}

\subsection{Plasmid preparation}

The pFAR4 derivative, pFAR4-CMV LUC BGH (pFAR4-LUC), which is a plasmid devoid of antibiotic resistance gene, was propagated using a dedicated bacterial producing strain [27]. The plasmid was purified using Nucleobond Endofree plasmid preparation kits (Macherey Nagel, Hoerdt, 
France). Endotoxin levels were validated using the LAL (Limulus Amoebocyte Lysate) procedure (Lonza, Verviers, Belgium).

pTG11, full name pTG11033 with 9514 bp was obtained from Transgene S. A. (Strasbourg, France). It encodes the luciferase gene under the cytomegalovirus promoter. pTG11 was propagated from Escherichia coli DH5a cultures. Supercoiled plasmid was isolated from bacteria with the standard alkaline lysis method, and purification was carried out with the Qiagen Mega Kit (Qiagen, Courtaboeuf, France) according to the manufacturer's instructions.

\subsection{Ultrasound exposure system for in vitro gene transfer}

The ultrasound system used in this study was previously described [28]. US were generated from a 0.5-inch diameter, IBMF-014 transducer with a centre frequency of $1 \mathrm{MHz}$ (Sofranel, Sartrouville, France). The transducer was placed in a custom made polystyrene tank filled with degassed pure water. A signal consisting of $1.0 \mathrm{MHz}$ centre frequency, $40 \%$ duty cycle and a pulse repetition frequency of $10 \mathrm{kHz}$ was generated by a $33220 \mathrm{~A}$ arbitrary function generator (Agilent technologies, Les Ulis, France) and amplified by a RF power amplifier (ADECE, Artannes sur Indre, France) was used as the input for the transducer. Peak negative pressure of $150 \mathrm{kPa}$ was used corresponding to an MI of 0.15 . Ultrasound stimulation time was set to $60 \mathrm{sec}$. The transducer was calibrated in a Perspex container using an HGL-200 PVDF bullet type hydrophone (Onda, Sunnyvale, CA) placed at $3 \mathrm{~cm}$, the natural focal distance of the transducer. The transducer was positioned in front of the sonoporation cuvette (Sarstedt AG \& Co, Nümbrecht, Germany). The attenuation of the cuvette walls was measured separately and found to be negligible (less than $10 \%$ ).

\subsection{Microbubble formulations}

The cationic lipid, DMAPAP, synthesized as previously described [25], was diluted in 5\% sucrose and placed in $2 \mathrm{~mL}$ vials containing $1 \mathrm{~mL}$ of lipid suspension. The vials were capped and air was displaced by perfluorobutane gas (Matrix Scientific, Columbia, SC, USA) at atmospheric pressure. MB were formed by vigorous mechanical agitation using a Vialmix system (DuPont Pharmaceuticals Company, Billerica, MA, USA) for 45 sec. PEGylated MBs were obtained post agitation by addition of $20 \%$ of home-made N-hydroxysuccinimide polyethylene glycol (PEG) - 2000 at pH 7.5. All samples were left for $10 \mathrm{~min}$ before use and were used within $1 \mathrm{~h}$ following agitation. Prior to pDNA interaction, approximatively $200 \mu \mathrm{L}$ of $\mathrm{MB}$ were collected into $1 \mathrm{~mL}$ syringe with a $27 \mathrm{~g}$ needle. The syringe was kept in vertical position with the plunger up for 2 min in order to separate MB by buoyancy. The largest MB formed a cake against the syringe plunger and the rest of the suspension 
containing monodisperse microbubbles were collected by pushing the plunger. Then pFAR4-LUC

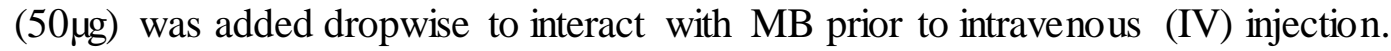

Cationic MB formulation with DOTAP lipid was also prepared as control for gene delivery. Briefly, a liposomal formulation of DSPC: DOTAP:DSPE-PEG2000 (0.7:0.2:0.1 molar ratio) was prepared in $10 \mathrm{mM}$ HEPES buffer, $\mathrm{pH} 7.4$ at a final concentration of $5 \mathrm{mg} / \mathrm{mL}$. This solution was freeze dried, and the vial headspace was replaced by $\mathrm{C}_{4} \mathrm{~F}_{10}$ gas. The vial was resuspended and activated by a mechanical agitation using a VialMix during $45 \mathrm{sec}$.

\subsection{In vitro sonoporation}

$1 \times 10^{5} \mathrm{HeLa}$ cells were grown on a resized Opticell ${ }^{\circledR}$ membrane $(10 \times 15 \mathrm{~mm})(\mathrm{Nunc} \mathrm{GmbH} \& \mathrm{Co} . \mathrm{KG}$, Langenselbold, Germany). The Opticell ${ }^{\circledR}$ membranes were transferred into polystyrene cuvettes (Sarstedt, Nümbrecht, Germany) containing $1.5 \mathrm{~mL}$ of OptiMEM medium (Invitrogen, Carlsbad, CA, USA) supplemented with 1\% FCS (Thermofisher, France). During sonoporation the cell medium was placed under gentle agitation using a magnetic stirrer. After sonoporation the membrane was placed in the incubator with the sonoporation medium on a 12-well cell culture plate. Sonoporation was performed using $1 \mu \mathrm{L}$ of Micromarker ${ }^{\mathrm{TM}} \mathrm{MB}$ (Visualsonics, Amsterdam, The Netherlands) and an equimolar amount of pTG11 $(2 \mu \mathrm{g})$ or luciferase-encoding pFAR4 plasmid DNA $(5 \mu \mathrm{g})$. Ultrasound parameters used were $1 \mathrm{MHz}, 150 \mathrm{kPa}, 40 \%$ duty cycle, $10 \mathrm{kHz}$ pulse repetition frequency and 60 sec. of insonation time. Gene transfer efficiency was evaluated $24 \mathrm{~h}$ after sonoporation by measuring the luciferase activity using a Lumat LB9507 luminometer (Berthold, Thoiry, France) as previously described [28]. For confocal microscopy analysis, pFAR4-LUC and PTG11 were labelled with Cy3 or Cy5 fluorophore dyes using Label IT® Nucleic Acid Labeling Reagents Mirus kit according to manufacturer's instructions.

\subsection{Size and Microbubbles counting using Tunable Resistive Pulse Sensing (TRPS)}

MBs obtained with $1 \mathrm{mg} / \mathrm{mL}$ of cationic lipids were analysed by the TRPS technique (Izon, France) as previously described [26]. The size and concentration were measured after microbubble PEGylation prior and post pDNA interaction. All measurements were performed in triplicate on a NP2000 nanopore, using $20 \mathrm{mM} \mathrm{NaCl}$ as electrolyte, and an applied pressure of $5 \mathrm{mbar}$. Certified

particles were used for calibration (CPC2000; mode size $1.90 \mu \mathrm{m}$; concentration $5.5 \times 10^{9}$ particles/mL). The sample statistics were obtained using IZON Science software. The median value, $\mathrm{d} 50$, represents the diameter at the 50th percentile. The size distribution is given by the d10-d90 range, which represent the MB population between the $10^{\text {th }}$ and the $90^{\text {th }}$ percentile. 


\subsection{Microbubble/DNA interaction}

The complexation of DNA with MB has been investigated by gel retardation assay. Several volumes $(0.5 ; 1 ; 2 ; 4 ; 8 ; 10 ; 12$ or $15 \mu \mathrm{L})$ of cationic microbubbles at lipid concentration of $1 \mathrm{mg} / \mathrm{mL}$ were mixed with $1 \mu \mathrm{g}$ of pFAR4-LUC in a final volume of $20 \mu \mathrm{L}$. MicroMarkerTM MBs, which have no ability to complex DNA, were used as control. After $5 \mathrm{~min}$ of complexation, solutions of mixed pDNA and MB were loaded onto a $0.6 \%$ agarose gel containing ethidium bromide and electrophoresis was performed in TAE buffer at $100 \mathrm{~V}$ during $45 \mathrm{~min}$. The DNA loading capacity was evaluated by increasing the quantity of DNA (from 0.1 to $2 \mu \mathrm{g}$ ) on a fixed quantity of microbubbles ( $2 \mu \mathrm{L}$ of microbubbles were used for this experiment). The gel was revealed under UV illumination.

\subsection{Acoustic properties}

The microbubble harmonic response to US was determined using a homemade set-up (Figure 2A). A $5 \mathrm{MHz}$ transducer (Panametrics, Olympus, Center Valley, USA flat transducer $13 \mathrm{~mm}$ diameter) connected to an oscilloscope (Tie-Pie, Sneek, Netherlands) was used for ultrasound detection.

For ultrasound emission, a 3Bop ultrasound generator (Image Guided Therapy, Pessac, France) connected to a 10-mm diameter Continuous Doppler probe (Blatek, State College PA, USA) at 1 $\mathrm{MHz}$ emission frequency. For each acoustic parameter, microbubbles $(1 \mathrm{mg} / \mathrm{mL})$ with and without pDNA $(17 \mu \mathrm{g})$ were diluted in degassed water at a concentration of approximatively $10^{7} \mathrm{MB} / \mathrm{mL}$ and placed in a cuvette. Carboxylated polystyrene particles (CPC1000; IZON Science) were used for reference as linear scatterer. Measurements were performed at different acoustic pressures, from 75 to $375 \mathrm{kPa}$, with a duty-cycle of $10 \%$ and 20 pulses of $100 \mu$ s. Results are means of 5 measurements for each parameter. The radio-frequency data acquired by the $5 \mathrm{MHz}$ transducer were processed with Matlab (Mathworks, Natick, USA). The echo from MB was windowed and converted into a power spectrum to determine the presence of harmonics (multiples of the fundamental emitted frequency), subharmonics (half the emitted frequency). The energy comprised in each harmonic was summed over the bandwidth of the pulse. Broadband signal was measured as the total energy in between harmonics and subharmonic peaks. Identical signal processing was applied to the linear scatters for reference. 


\subsection{Ultrasound imaging using microbubbles}

To assess the instantaneous biodistribution of $\mathrm{MB}$ in vivo, we performed ultrasonography on $\mathrm{BALB} / \mathrm{cJ}$ mice. Mice were anesthetized with 3\% isoflurane (Isovet, Virbac, France) in air for induction, and maintained at $1.5 \%$ for imaging. Mice were then shaved using a depilatory cream, and placed on the heating pad of the Vevo Imaging Station (Visualsonics). A catheter was inserted in the tail vein using a $27 \mathrm{~g}$ needle. In vivo imaging of microbubbles was performed using a VEVO2100 imaging system (Visualsonics) with an $18 \mathrm{MHz}$ probe (MS250) allowing non-linear imaging. The probe was fixed and placed in axial plane to image the whole liver. Images were acquired using the contrast mode acquisition, with low output power setting (4\%) and a 10 to $14 \mathrm{~Hz}$ frame rate. MBpDNA complexes were prepared prior to injection with a cationic lipid concentration of $2 \mathrm{mg} / \mathrm{mL}$ and $50 \mu \mathrm{g}$ of pFAR4-LUC. MB suspension $\left(200 \mu \mathrm{L}, 2.7 \times 10^{7} \mathrm{MB}\right)$ coupled with pDNA were injected via the catheter and then an additional $100 \mu \mathrm{L}$ saline flush was performed. The contrast uptake sequence in the liver was stored during $120 \mathrm{sec}$.

\subsection{Targeted gene delivery}

The gene delivery step was performed using the 3Bop ultrasound generator, a specific device allowing high duty cycles and high intensity ultrasound emission, using the same continuous Doppler probe. The system allowed the generation of any duty cycle and a peak Negative Pressure of $1.6 \mathrm{MPa}$ at its focal zone $(22 \mathrm{~mm})$, the emission diagram of the system was provided by the 3Bop manufacturer and is displayed in supplementary data (Supplementary Figure 1).

A 2-cm spacer consisting on a rigid tube filled with ultrasonic gel was used to ensure that the focal zone was located below the skin, in the liver parenchyma. The sonication probe was positioned on the right flank of the mouse, in the axial plane, with a $45^{\circ}$ angle to the sagittal plane. Adequate positioning was ensured by ultrasound imaging: the gel contact between the sonication probe and the skin, the distance to the skin of the probe and the expected location of the focal zone in right lobe of the liver was assessed using the imaging probe (Supplementary Figure 2).

Evaluation of MB concentration dynamics in the liver was obtained analysing B-mode image sequence from the ultrasound scanner (Figure 3). Briefly a user-defined ROI was placed in the liver and backscattered echo amplitude was measured using the VEVOLAB quantification software. This software provides linearized acoustic amplitudes from linear and non- linear imaging modes along time. Normalized fundamental acoustic response from microbubbles was built after two separate experiments of bolus injection with and without sonoporation. Since sonoporation could not be 
synchronized to B-mode imaging, white artefacts due to ongoing sonoporation (left of figure 4) could be seen on some frames.

MB-pDNA complexes were prepared and administrated as described above. Optimal sonoporation conditions were determined by varying US parameters after microbubble IV injection on BALB/cJ mice $(n=5)$.

Bolus injections or continuous infusion using a syringe pump (Pump 11 Elite, Havard Apparatus) during 1 or 3 min were tested to determine optimal transfection condition. The Pulse Repetition Frequency (PRF) was kept constant at $100 \mathrm{~Hz}$. Multiple Duty Cycles (DC) were tested but the total ultrasound exposure time was kept constant, therefore the following DC and duration of the procedure time were used: 10\% DC and 2 min sonoporation time, 20\% DC and 1 min sonoporation time, 40\% DC and $30 \mathrm{sec}$ sonoporation time with an acoustic pressure of $480 \mathrm{kPa}$ or $750 \mathrm{kPa}$. A combination of multiple ultrasound emission acoustical pressures was also tested to determine the optimal settings. 480, 750, 930 and $1125 \mathrm{kPa}$ of peak negative pressure pulses were tested with $20 \%$ DC.

The optimal sonoporation parameters were used to compare gene transfer for free pDNA, pDNA coinjected with MicroMarkerTM MB or adsorbed on cationic $\mathrm{MB}(\mathrm{n}=9)$.

Luciferase expression was followed by bioluminescence imaging. Briefly, mice were depilated $24 \mathrm{~h}$ before, anesthetized as described above and then injected intraperitoneally with $150 \mathrm{mg} / \mathrm{kg}$ of luciferin (Xenolight D luciferin potassium salt, Perkin Elmer) 5 min before image acquisition. Bioluminescence was acquired with a Photon imager RT (Biospacelab, France) imaging system during $10 \mathrm{~min}$, placing 3 to 5 animals at a time in the device. This real-time bioluminescence imaging allowed to detect the plateau of photon emission for each individual. This time frame was used to calculate the photon emission in $\mathrm{ph} / \mathrm{s} / \mathrm{cm}^{2} / \mathrm{sr}$ within a constant pre-defined ellipsoid region of interest, placed in the liver on each mouse followed. Statistical analysis of bioluminescence activity was performed with GraphPad Prism software (version 5.00, GraphPad Software, San Diego, CA, USA) using a non-parametric Mann-Whitney test between 2 groups. Differences were considered statistically significant for a $p$-value $<0.05$.

\subsection{Histological assessments}

Livers were collected before and 1, 3 and 7 days after insonation. They were placed in a solution of $4 \%$ paraformaldehyde overnight and then stored in $70 \%$ ethanol. Samples were then included in paraffin using an automated device (VIP, Tissue-Tek, Sakura). Livers were then cut in $4 \mu \mathrm{m}$-thick 
slices every $150 \mu \mathrm{m}$ and stained with haematoxylin and eosin. Histological slides were analysed by a pathologist and scores according to toxicity criteria.

\subsection{Toxicity assay}

To assess liver toxicity, blood $(100 \mu \mathrm{L})$ was collected in the retro-orbital sinus before and 1,2 and 7 days after sonoporation, with Pasteur pipettes prepared with $20 \mu \mathrm{L}$ of $50 \mathrm{mg} / \mathrm{mL}$ heparin. Blood samples were then centrifuged at $4^{\circ} \mathrm{C}$ for $20 \mathrm{~min}$ at $4000 \mathrm{rpm}$. Plasma was then collected and stored at $-20^{\circ} \mathrm{C}$ for further analysis. Alanine amino transferase (ALAT) and aspartate amino transferase (ASAT) activities were determined at $37^{\circ} \mathrm{C}$ using end point methods. Absorbance decreases to 340 nm were measured automatically on Modular@ biochemistry analyser (Roche, Meylan, France) using $20 \mu \mathrm{L}$ of plasma samples. Results were expressed in International Unit per litre (IU/L). Methods were linear until $900 \mathrm{IU} / \mathrm{L}$ and $880 \mathrm{IU} / \mathrm{L}$ for ASAT and ALAT, respectively. Validity of activities was assessed using quality controls, Precinorm $\mathrm{U} \circledR$ and Precinorm H® (Roche, Meylan, France) during sample determinations.

\subsection{Immunofluorescence labelling and fluorescence microscopy analyses}

Liver tissues were harvested, frozen in isopentane immersed in liquid nitrogen for $1 \mathrm{~min}$, and stored at $-80^{\circ} \mathrm{C}$ until the preparation of histology slides. Five micron frozen tissues sections were placed on superfrost plus slides and stored at $-80^{\circ} \mathrm{C}$ before immunofluorescence. These liver slices were first fixed in cooled acetone for $5 \mathrm{~min}$. After 3 washes in phosphate buffer saline (PBS $10 \mathrm{mM}$ ), saturation of unspecific sites was done by incubation of slices with PBS supplemented with $10 \%$ of bovine serum albumin for $20 \mathrm{~min}$ at room temperature. Liver sections were co-incubated with 1/1000 antiFirefly Luciferase rabbit antibody (ab21176, Abcam, Cambridge, UK) and 1/100 rat anti-mouse CD31 (PECAM-1) antibody (550274 BD, Pharmingen, US) overnight at $4^{\circ} \mathrm{C}$. The slices were washed three times and incubated with the secondary antibodies (1/400 Goat Anti-rabbit IgG $(\mathrm{H}+\mathrm{L})$, CFTM488A antibody SAB4600234; Sigma Aldrich, France and 1/400 rat anti-mouse IgG Rhodamine antibody SAB3700552 Sigma Aldrich) for $30 \mathrm{~min}$ at room temperature. Finally, cell nuclei were stained with 4',6-Diamidino-2-phenylindole dihydrochloride (DAPI D9542; SIGMA). Photographs (1000x magnification) were taken on a Zeiss fluorescence microscope (Carl Zeiss SAS, Marly Le Roi, France).

All animal experiments were approved by the local ethics committee according to the procedure agreement \#02166.04. 


\section{Results}

\subsection{Plasmid size influence on gene transfer efficiency}

To both increase transfection efficiency and transgene expression, the pFAR4 miniplasmid DNA that is devoid of antibiotic resistance marker and has a reduced size was used as a gene vector [27]. The luciferase reporter gene was chosen to monitor in vivo gene expression [29]. We hypothesized that the small size of the pFAR4-LUC miniplasmid could be advantageous for US associated microbubble gene delivery. This was first evaluated in vitro using US parameters that has been previously optimized for gene delivery with MicroMarker ${ }^{\mathrm{TM}} \mathrm{MB}$ [28]. As comparison, we used pTG11 pDNA which encodes as well for luciferase gene under CMV promotor but has a larger size $(\sim 9.5 \mathrm{~kb})$ than pFAR4-LUC $(\sim 3.7 \mathrm{~kb})$. Following sonoporation, gene expression obtained with the pFAR4 derivative was 20-fold higher than that with pTG11 (Figure 1A) in absence and in presence of microbubbles. Confocal microscopy analysis revealed that $1 \mathrm{~h}$ post-sonoporation, pFAR4-LUC was found closer to the nucleus area as compared to pTG11 (Figure 1B).

A

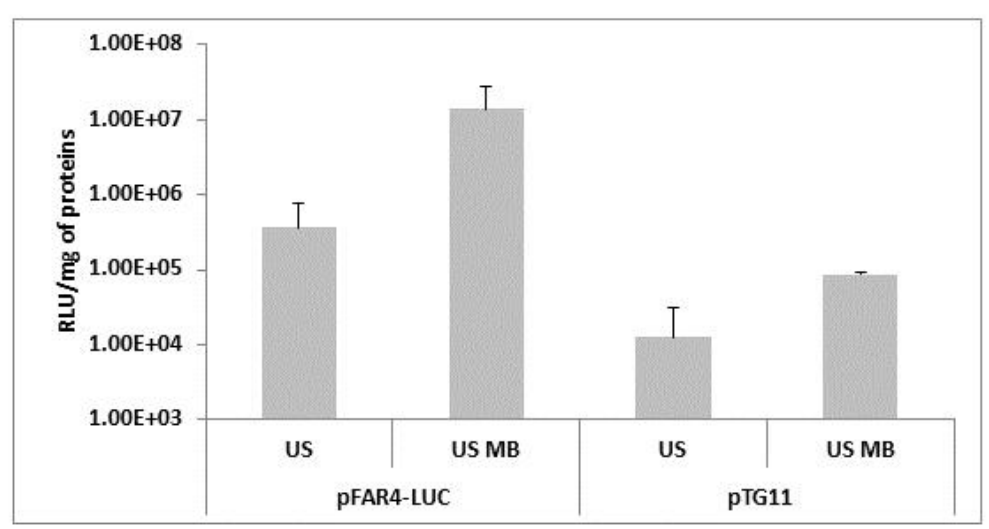

B
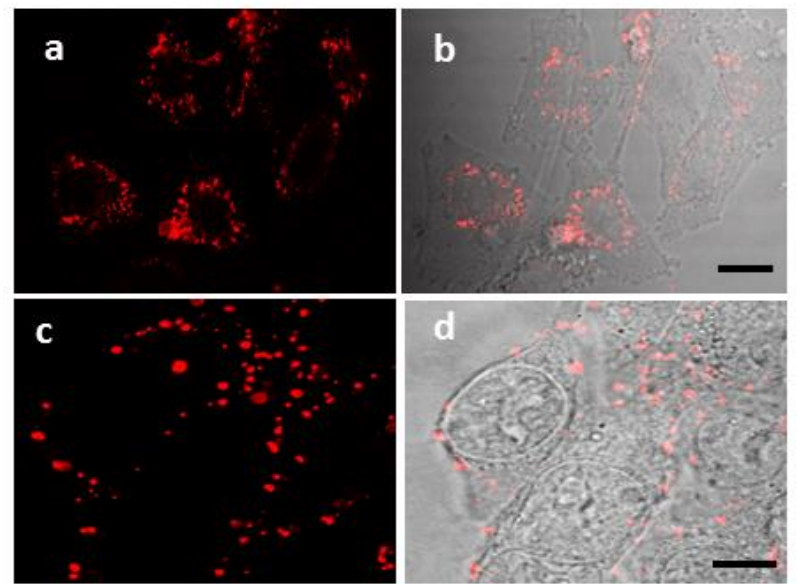

Figure 1: Adherent HeLa cells were sonoporated at $1 \mathrm{MHz}$ of frequency, $150 \mathrm{kPa}, 40 \% \mathrm{DC}, 1 \mathrm{~min}$ of exposure time in the presence Micromarker ${ }^{\mathrm{TM}}$ bubbles of either $2 \mu \mathrm{g} / \mathrm{mL}$ of pFAR4-LUC or pTG11 
plasmids both encoding luciferase reporter gene. A) Luciferase activity was determined $24 \mathrm{~h}$ postsonoporation and values are expressed as mean of triplicate experiments performed 3 times. B) Cells were sonoporated in the presence of Micromarker ${ }^{\mathrm{TM}}$ microbubbles and of either $2 \mu \mathrm{g} / \mathrm{mL}$ of pFAR4LUC ( $a$ and b) or pTG11 (c and d) labelled with Cy3 probe (red) with the same acoustic parameters as in A. The transfection medium was removed and cells were further incubated for 30 min at $37^{\circ} \mathrm{C}$ before fixation. a and c (fluorescence images); $b$ and $d$ (merge of fluorescence and bright field images) Scale bar: $10 \mu \mathrm{m}$.

\subsection{Microbubble preparation and characterization}

To produce cationic MB, we used a bicatenar dimyristoyl lipid with a branched polyamine head able to interact with pDNA using a low lipid amount (Figure 2 A). This lipid was selected from a series of cationic lipids for its ability to transfect cell with high efficiency [25].

In order to avoid the accumulation of cationic MB into the lung post intravenous injection, we chose to PEGylate them. As the insertion of PEG-lipid into microbubbles formulation was leading to foam formation, PEGylation was performed post microbubble formation, using an N-hydroxysuccinimide PEG able to react on $20 \%$ of the amines of the cationic lipid. The rest of the amines of the cationic lipid were therefore available for the interaction with pDNA, which was added dropwise on the microbubble suspension.

The concentration and size range of the MB were obtained using the TRPS technique. The characterisation of the positively charged MB solely consisting in DMAPAP lipid has been described previously [26]. The characterisation of PEGylated MB with and without pDNA is given in Table 1. Shaking a suspension of cationic lipid $(1 \mathrm{mg} / \mathrm{mL})$ with perfluorobutane led to $3 \times 10^{8} \mathrm{MB} / \mathrm{mL}$ with a size centred on $2.05 \mu \mathrm{m}$ and a low polydispersity. The pDNA interaction on the microbubble surface had no influence on the microbubble concentration and size. To demonstrate the loading of pDNA on $\mathrm{MB}$, confocal microscopy analysis was performed on MB complexed with fluorescently labelled pDNA (Figure 2B). The fluorescent pDNA was found all around the surface of MB demonstrating an efficient loading of pDNA. 
Table 1: Microbubble concentration, median size (d50) and size range between the $10^{\text {th }}$ and the $90^{\text {th }}$ percentile obtained by TRPS technique.

$\begin{array}{llll}\text { Formulation } & \text { Concentration }(\mathrm{MB} / \mathrm{mL}) & \mathrm{d} 50(\mu \mathrm{m}) & \mathrm{d} 10-\mathrm{d})\end{array}$

\begin{tabular}{llll}
\hline DMAPAP MB & $2.7 \pm 0.3 \times 10^{8}$ & $2.05 \pm 0.04$ & $1.53-3.16$
\end{tabular}

DMAPAP MB +

pFAR4-LUC

$$
2.7 \pm 0.4 \times 10^{8} \quad 2.07 \pm 0.02 \quad 1.54-3.12
$$

Gel retardation assay showed that DMAPAP microbubbles interacted with pDNA, while the neutral microbubbles MicroMarker ${ }^{\mathrm{TM}}$ did not (Figure 2C). A significant reduction in pDNA migration was observed starting from $8 \mu \mathrm{L}$ of DMAPAP MB. The absence of migration was complete when increasing the volume of MB. In marked contrast, a migration of pDNA was observed whatever the volume of Micromarker TM MB used. A gel retardation assay was also performed with a standard cationic MB formulation made with DSPC:DOTAP and DSPE-PEG 2000 (Figure 2D). DMAPAP MB were found more able to carry plasmid DNA than DOTAP-based MB.

A

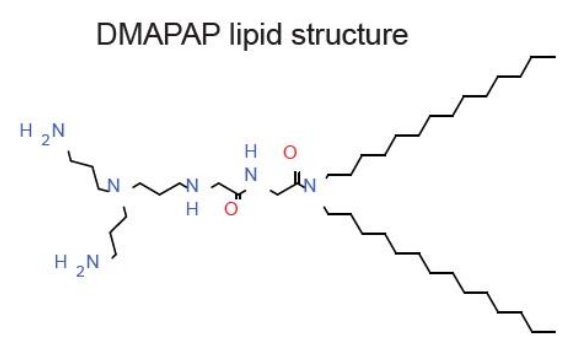

C

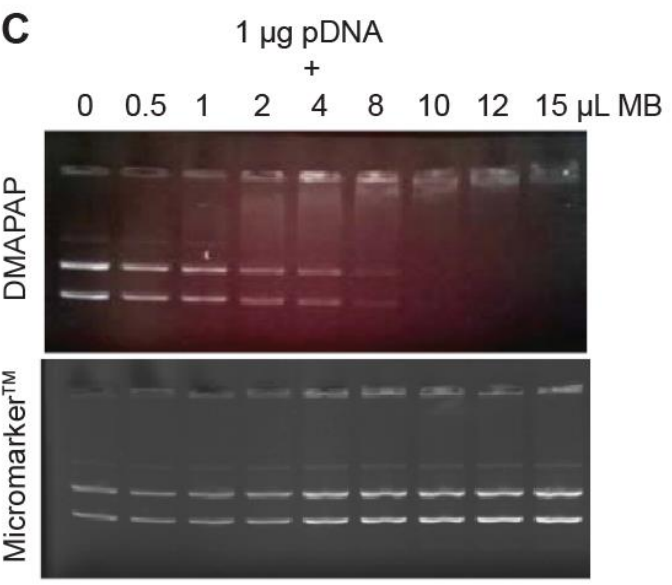

B

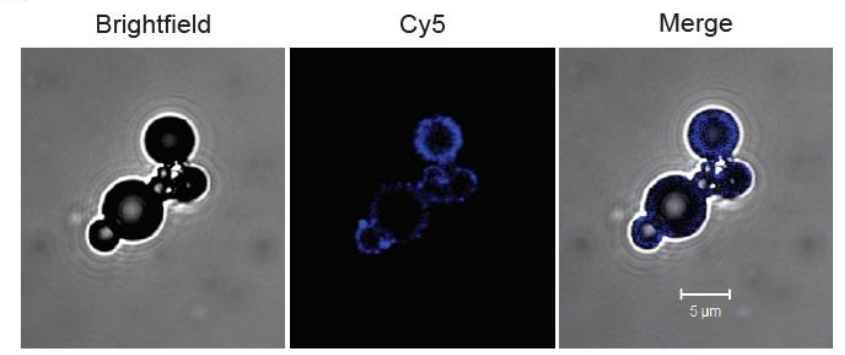

D

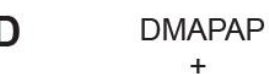

$\begin{array}{lllll}0.1 & 0.2 & 0.5 & 1 & 2\end{array}$

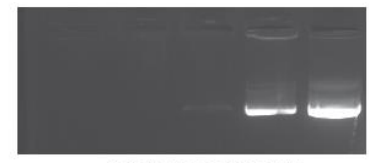

DSPC:DOTAP

$\begin{array}{lllll}0.1 & 0.2 & 0.5 & 1 & 2\end{array}$

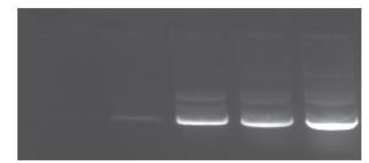

HEPES
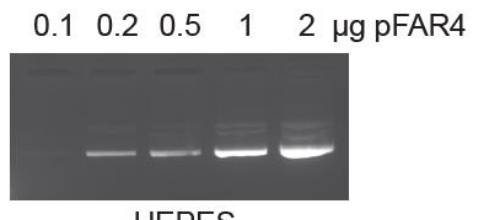

HEPES

$\begin{array}{lllll}0.1 & 0.2 & 0.5 & 1 & 2 \mu \mathrm{p} \text { pFAR4 }\end{array}$

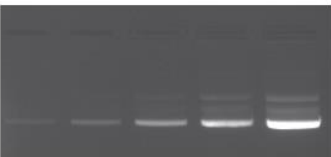

Figure 2: Complexation of pDNA on cationic charged MB. A) Structure of DMAPAP lipid, B) DMAPAP microbubbles complexing a Cy5-labelled plasmid DNA were imaged by confocal 
microscopy C) Gel shift assay was performed to evaluate the interactions of $1 \mu \mathrm{g}$ pTG11 with increasing volume of DMAPAP, MicroMarker ${ }^{\mathrm{TM}} \mathrm{MB}$. D) Gel shift assay was performed to evaluate the plasmid DNA loading capacity of DMAPAP microbubbles compared to DOTAP microbubbles.

To assess the stability of MB and the influence of PEGylation, complexes were made either with non PEGylated or PEGylated MB were analysed by flow cytometry at 5 and 10 min post-complexation (Supplementary Figure 3). Intact MB exhibited a specific serpentine pattern in the forward-scatter vs. side-scatter plots as previously reported [30]. Destabilized MB led to the formation of lipoplexes that can be observed as dots below the serpentine pattern. The evolution of percenta ge as function of time clearly indicates that the PEGylation has also a positive influence on MB stability once complexed with pDNA. The efficiency of DMAPAP-MB for gene delivery in vitro following sonoporation was compared to that obtained with DSPC:DOTAP MB (supplementary Figure 4). When compared to DMAPAP MB, luciferase activity obtained with DOTAP MB was 100- and 30-fold lower in absence and in the presence of US, respectively.

A
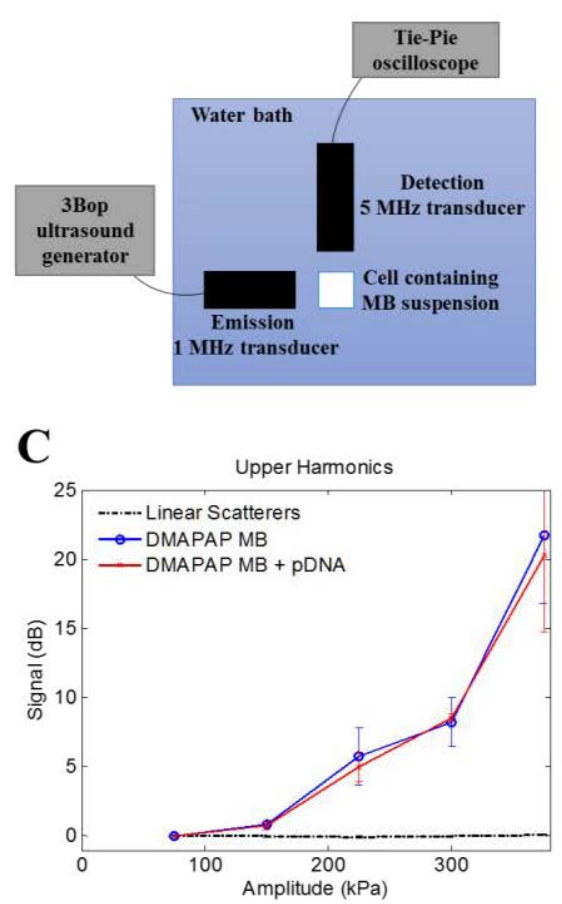

B
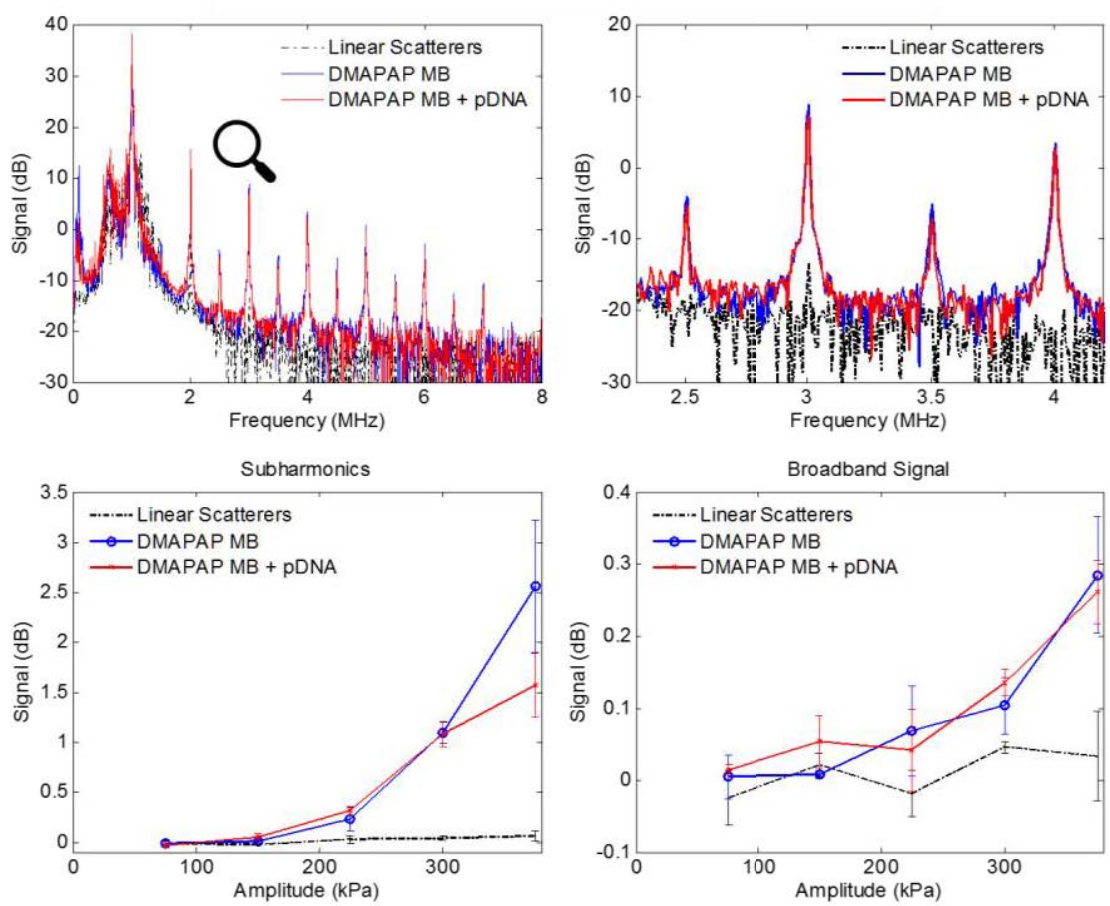

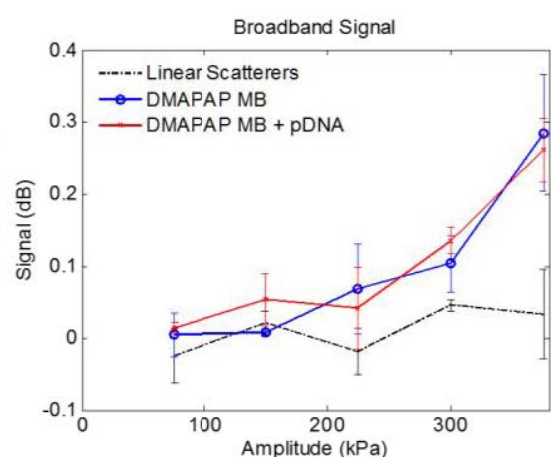

Figure 3: Microbubble oscillation and destruction under ultrasound. (A) Illustration of the homemade set-up for acoustic measurements. (B) Power spectrum showing harmonics and subharmonics linked to the nonlinear oscillations of the microbubbles. (C) Echo intensity accumulated in the harmonics, subharmonics and in between as broadband signal. 
We then evaluated the acoustic activity of MB using a $5 \mathrm{MHz}$ transducer as ultrasound detector and a $1 \mathrm{MHz}$ Doppler probe used for the in vivo experiments as ultrasound emitter with increased acoustic pressures. To determine the energy required for microbubble oscillations and the energy leading to microbubble destruction, acoustic measurements were performed in water bath onto suspension of $\mathrm{MB}$, using an acoustic pressure ranging from 75 to $375 \mathrm{kPa}$ (Figure $3 \mathrm{~A}$ ).

Positively charged MB was sensitive to ultrasound, as evidenced by the presence of upper harmonic and subharmonic frequency signal responses (Figure 3B). Both upper harmonic and subharmonic total intensity signals were increased as a function of the ultrasound acoustic pressure, as regard to linear scatterers which are not prone to oscillation (Figure 3C). An increased broadband noise was obtained for MB, whereas stable broadband noise was obtained for linear scatterers (Figure 3C). The increased broadband is reflecting the MB destruction starting at an acoustic pressure of $375 \mathrm{kPa}$. It is important to point out that the association of pDNA on the MB surface did not impact their acoustic response (Figure $3 \mathrm{~B}$ and $\mathrm{C}$ ).

\subsection{Image guided study}

In vivo experiments were performed on $\mathrm{BALB} / \mathrm{cJ}$ mice under ultrasound imaging to follow the kinetic of $\mathrm{MB}$ accumulation into the liver after tail vein injection and to assess the effect of insonation conditions on MB destruction. First, the set-up had to be adjusted to obtain the correct positioning of the ultrasound emitting transducer, the ultrasound imaging probe for mice liver observation (Supplementary Figure 2).

Mouse liver could be observed in both B-mode and contrast mode from this axial view (Figure 4A). After DMAPAP MB administration, contrast uptake in the liver could be assessed in conventional Bmode (Figure 4B). The kinetics of microbubbles accumulation in the liver could be monitored and showed that MB remained visible during at least 1 min post-injection, with a maximum accumulation within the liver at $20 \mathrm{sec}$ (Figure 4D, Figure 4E black squares). Most of MB signal was lost right after sonoporation (750 kPa, DC 20\%, $60 \mathrm{sec}$, PRF $100 \mathrm{~Hz}$ ) (Figure 4C, Figure 4E gray circles) because of microbubble destruction (Figure 4E).

As a comparison, Micromarker ${ }^{\mathrm{TM}} \mathrm{MB}$ kinetics of accumulation in the liver was also monitored. In absence of sonoporation, Micromarker ${ }^{\mathrm{TM}} \mathrm{MB}$ lasted longer in the circulation as opposed to DMAPAP MB (Supplementary Figure 5A). Upon sonoporation, both Micromarker ${ }^{\mathrm{TM}}$ and DMAPAP 
contrast intensities in B-mode decreased (Supplementary Figure 5B). No more contrast uptake could be observed at the end of the sonoporation sequence for both MBs.

The contrast enhancement obtained after MB administration and the observation of their fate allowed us to test and select appropriate ultrasound parameters for gene transfer in the liver. In particular, we could select the appropriate time to turn on the ultrasound emission thanks to the observation of a fully contrasted liver $20 \mathrm{sec}$ post-injection.
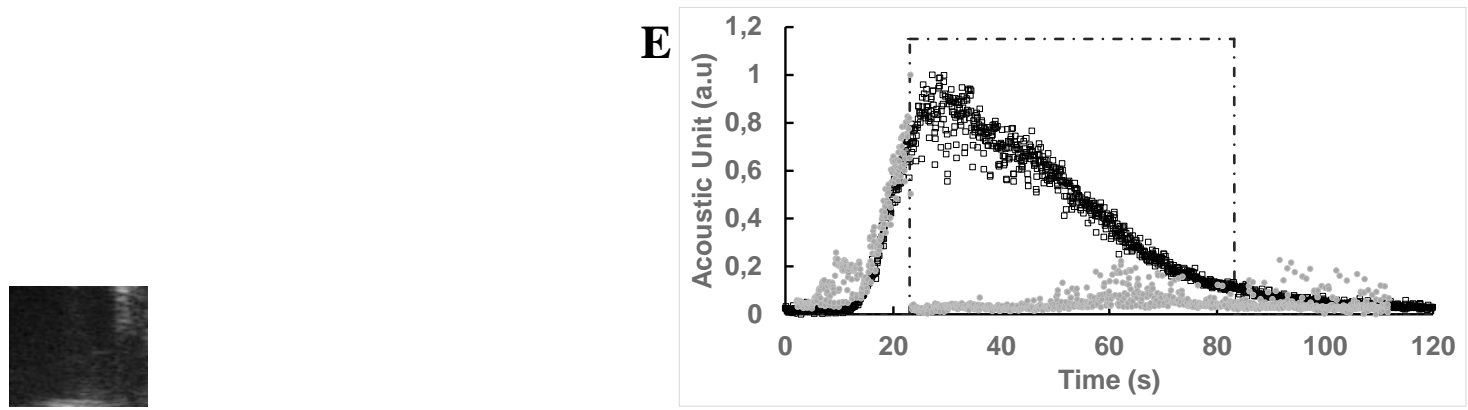

Figure 4: Ultrasound imaging and kinetic of $\mathrm{MB}$ accumulation in liver.

Liver US imaging performed (A) before microbubble injection, (B) after microbubble injection, (C) during sonoporation and (D) after sonoporation. (E) Kinetics of microbubbles accumulation after bolus injection, with (grey circles, •) and without (black squares, a) sonoporation. Normalized acoustic amplitude of linear response from microbubbles is displayed over time. Dashed lines represent the time window of sonoporation.

\subsection{Optimisation of the protocol for in vivo gene transfer}

In vivo sonoporation conditions require a number of adjustments to obtain efficient gene transfer into the liver. To identify the optimal parameters of sonoporation, the next experiments were performed, under ultrasound imaging guidance, and transfection efficiency of luciferase-encoding pFAR4 was assessed by optical luminescence imaging.

First, we evaluated the impact of the injection speed on gene transfer at a constant PRF. The shorter the injection was, the higher the gene expression level was, indicating that a maximal amount of 
microbubbles reaching the liver is required to get optimal gene transfer (Figure 5A). Therefore, a bolus injection was used for the next experiments.

Second, we investigated the US parameters in terms of duty cycle and energy optimisation. We found that, using a constant total ultrasound exposure time and acoustic pressure, of $480 \mathrm{kPa}$ and $750 \mathrm{kPa}$, and varying the duty cycle, duration of $2 \mathrm{~ms}$ over $10 \mathrm{~ms}$, the transfection level was optimal (Figure $5 B)$.

Moreover, varying the energy from $480 \mathrm{kPa}$ to $930 \mathrm{kPa}$, while maintaining the duty cycle constant significantly improved the transfection level (more than 10-fold) compared to the control without US (Figure 5C). At higher energy (1125 kPa), despite a stronger level obtained on 2 mice, a lethal effect was observed for 3 others. The highest nontoxic acoustic power, $930 \mathrm{kPa}$, was therefore chosen as optimal parameter.

According to all these observations, we finally selected the following conditions as the optimal ones: a bolus injection of $\mathrm{MB}, 930 \mathrm{kPa}$ as ultrasound acoustic pressure with a duty cycle of $20 \%$, with an ultrasound exposure applied for $20 \mathrm{sec}$ post-MB injection.

These ultrasound conditions were used to compare the transfection efficiency obtained 2 days after the administration of pDNA either alone or associated with DMAPAP positively charged MB (Figure 5D). Upon ultrasound exposure, the luciferase activity was significantly increased (15-fold) for the group receiving DMAPAP MB/pDNA complexes, compared to the mice injected with pDNA alone followed by insonation. Therefore, the complexation of pDNA on MB led to an increased gene expression likely by improving the amount of pDNA reaching the liver. To get a clear comparison between DMAPAP MB/pDNA complexes and the lipoplexes counterpart, we assessed the gene transfer efficiency of DMAPAP lipoplexes (LPX) using the same conditions for DMAPAP MB as in Figure 5E. The luminescence intensity obtained with LPX without or with US application was very low and close to that of pDNA alone. Representative images of 3 mice sonoporated with DMAPAP MB and LPX both complexed with pFAR-Luc were shown in Figure 5F. Mice injected with LPX exhibited a background signal whilst those injected with DMAPAP MB showed bright bioluminescence signals. 
A

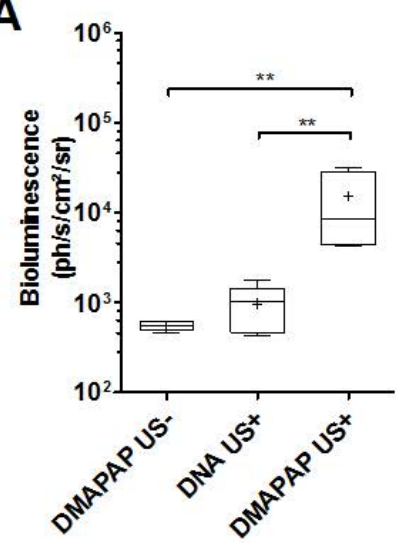

D

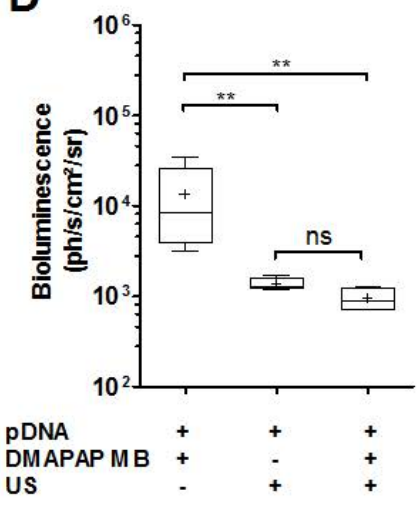

B

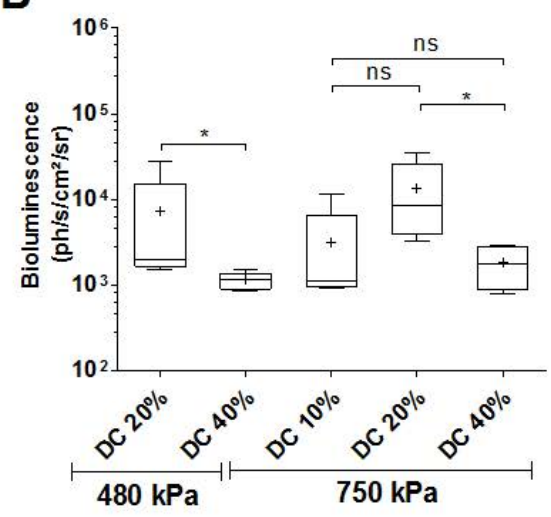

E

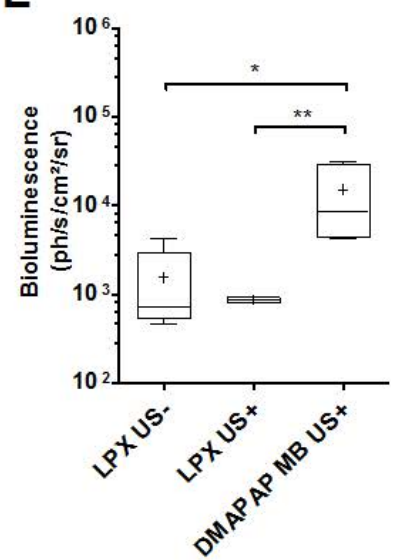

C

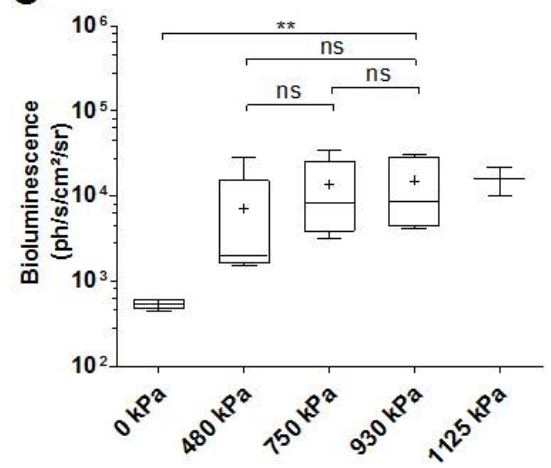

$\mathbf{F}$

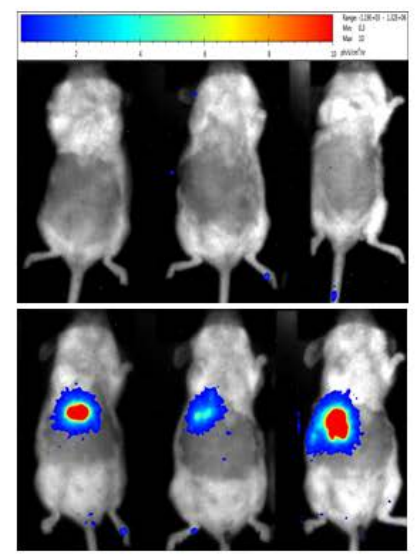

Figure 5: Influence of US parameters on in vivo gene transfection efficiency.

Bioluminescence reporter gene expression obtained 2 days post-administration of pDNA injected either alone or complexed with DMAPAP MB followed by US exposure with varied parameters: (A) the injection speed (using the following parameters: $1 \mathrm{MHz}, 750 \mathrm{kPa}$; DC 20\%); (B) the US dutycycle; (C) the acoustic pressure; (D) the injection of pDNA alone or complexed with microbubbles with or without US application (1 MHz, $930 \mathrm{kPa} ; 100 \mathrm{~Hz}$ PRF; DC 20\%; 6000 cycles); (E) the injection of DMAPAP LPX with or without US application (1 MHz, 930 kPa; $100 \mathrm{~Hz}$ PRF; DC 20\%; 6000 cycles); (F) Bioluminescence images obtained 2-days post-injection of DMAPAP LPX (top) and DMAPAP microbubbles (bottom) both followed by similar US application. Values represent box and whiskers (median, $10^{\text {th }}$ and $90^{\text {th }}$ percentiles) of bioluminescence levels $(n=5)$.

In order to evaluate the long-term duration of gene expression, we performed a second set of experiments by following the luciferase activity for a longer period of time, 180 days, and compared the efficacy of DMAPAP MB to commercially available MicroMarker ${ }^{\mathrm{TM}}$ MB (Figure 6). At day 1, the level of gene transfer was equivalent for all groups. At day 2, the level of gene transfer dropped down only when DNA was not injected with MB, reaching the background noise level 30 days post- 
sonoporation. No difference was found between groups injected with pDNA complexed with positively charged $\mathrm{MB}$ or co-injected with MicroMarker ${ }^{\mathrm{TM}} \mathrm{MB}$ at day 1 and day 2 . However, for longer period of time, a clear significant difference was observed between these two groups. Whilst the level obtained with the group injected with pDNA complexed with positively charged MB was stable over 180 days that of mice injected with pDNA and MicroMarker ${ }^{\mathrm{TM}}$ MB dropped down. Note that statistically significant difference between these two groups was found from 8 days postsonoporation.

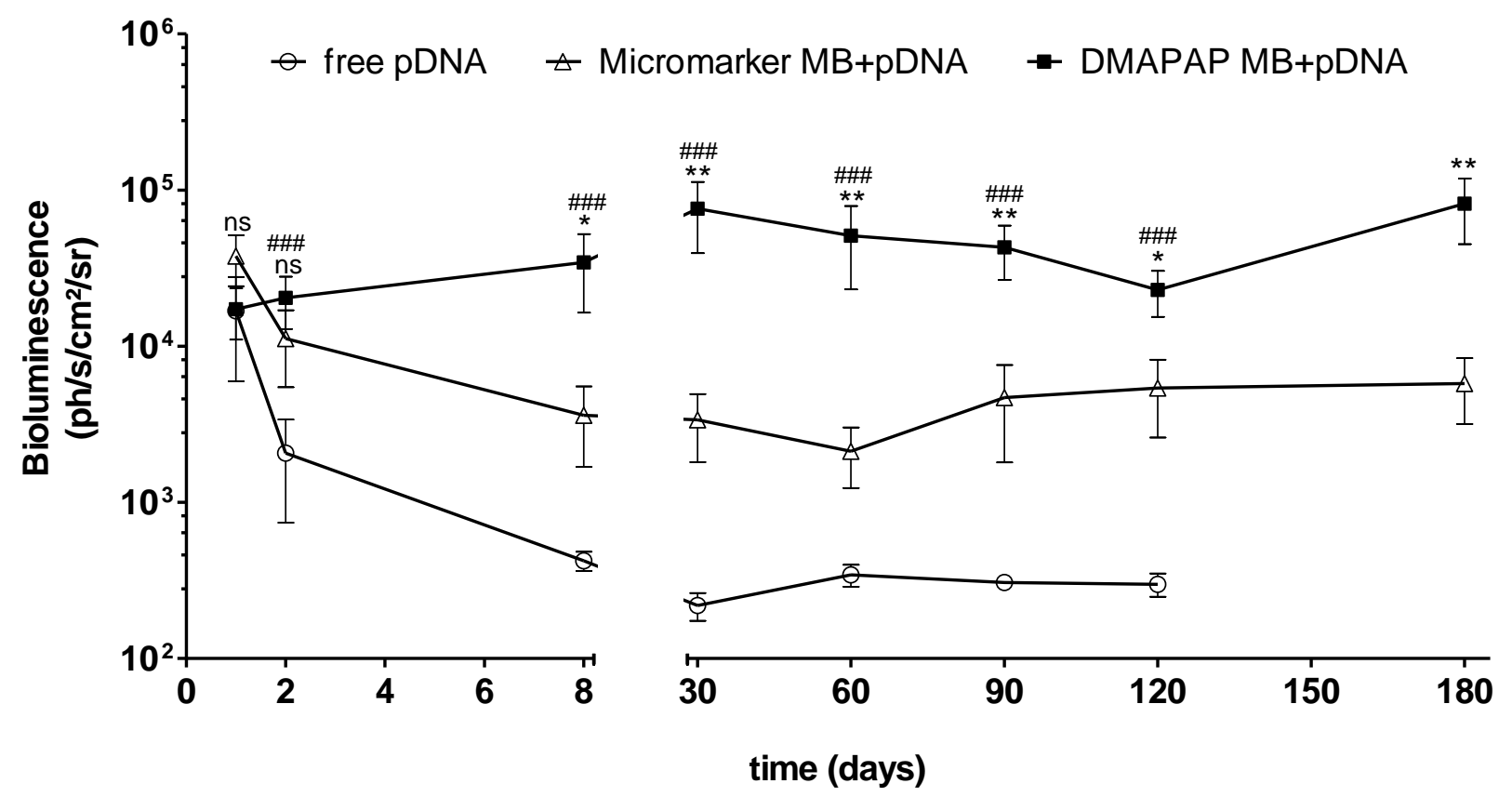

Figure 6: Long lasting luciferase gene expression in the liver following sonoporation with DMAPAP/pFAR4-LUC complexes.

Injection of DMAPAP MB complexed with pFAR4-LUC followed by sonoporation led to a longterm luciferase expression in the liver. Mice were injected with either free pDNA (O), pDNA associated with DMAPAP microbubbles (ם) and pDNA co-injected with MicroMarker ${ }^{\mathrm{TM}}$ MBs $(\Delta)$ followed by US exposure with optimal parameters (1 MHz, $930 \mathrm{kPa} ; 100 \mathrm{~Hz}$ PRF; DC 20\%; 6000 cycles). Values are means \pm standard errors, $n=9$, \# represent statistics for pDNA vs DMAPAP $\mathrm{MB}+\mathrm{pDNA}$ and $*$ for DMAPAP MB+pDNA vs MicroMarker ${ }^{\mathrm{TM}} \mathrm{MB}+\mathrm{pDNA}$; one symbol $p$ value $<0.05$, two symbols $p$-value $<0.01$, three symbols $p$-value $<0.001$.

To evaluate the toxicity of the protocol, blood was collected prior sonoporation, then $24 \mathrm{~h}, 48 \mathrm{~h}$ and 7 days post-treatment. The aspartate aminotransferase (ASAT) and alanine aminotransferase (ALAT) 
blood levels were measured as biomarkers of liver toxicity. As shown in Table 2, no signs of toxicity were observed for all groups tested apart from the group treated with positively charged microbubbles with sonoporation which exhibited a transient ele vation of transaminases over 1 to 2 days. Normal levels of those transaminases were recovered at day 7.

Table 2: Quantification of transaminases blood levels 1, 2 and 7 days after sonoporation.

\begin{tabular}{lcccc}
\hline \multirow{2}{*}{ Treatment } & \multicolumn{4}{c}{ ASAT (IU/L) } \\
& Day 0 & Day 1 & Day 2 & Day 7 \\
\hline NaCl & $42 \pm 6$ & $55 \pm 22$ & $42 \pm 6$ & $38 \pm 6$ \\
pDNA +US & $62 \pm 11$ & $55 \pm 9$ & $38 \pm 5$ & $35 \pm 4$ \\
MicroMarker MB +pDNA +US & $44 \pm 9$ & $47 \pm 4$ & $49 \pm 7$ & $55 \pm 8$ \\
DMAPAP MB +pDNA +US & $88 \pm 16$ & $187 \pm 51$ & $79 \pm 13$ & $55 \pm 4$ \\
\hline & Day 0 & DLAT (IU/L) \\
& $41 \pm 8$ & $33 \pm 4$ & $34 \pm 5$ & $31 \pm 4$ \\
\hline NaCl & $27 \pm 3$ & $64 \pm 12$ & $39 \pm 7$ & $29 \pm 5$ \\
pDNA +US & $36 \pm 4$ & $52 \pm 6$ & $38 \pm 11$ & $53 \pm 14$ \\
MicroMarker MB +pDNA +US & $61 \pm 6$ & $173 \pm 25$ & $107 \pm 16$ & $53 \pm 8$ \\
DMAPAP MB +pDNA +US & \multicolumn{4}{c}{ Day 2 } \\
\hline
\end{tabular}

Values shown are mean $\pm S D$ of 5 measurements.

Histological analyses of livers from treated mice were also performed. The use of DMAPAP MB was inducing more tissue damages compared to MicroMarker ${ }^{\mathrm{TM}} \mathrm{MB}$. At day 1, very few spots of lobular hepatitis were found (Figure 7, arrows). These spots were not visible at day 7 in the MicroMarker ${ }^{\mathrm{TM}}$ MB group. The use of DMAPAP MB seemed to induce subcapsular necrotic areas covering less than $5 \%$ of the tissue one day (Figure 7, stars). At day 7, lobular hepatitis foci and smaller sub capsular necrosis areas were still observable. Note that the data were comparable to the observations previously reported by Anderson et al. [10]. 

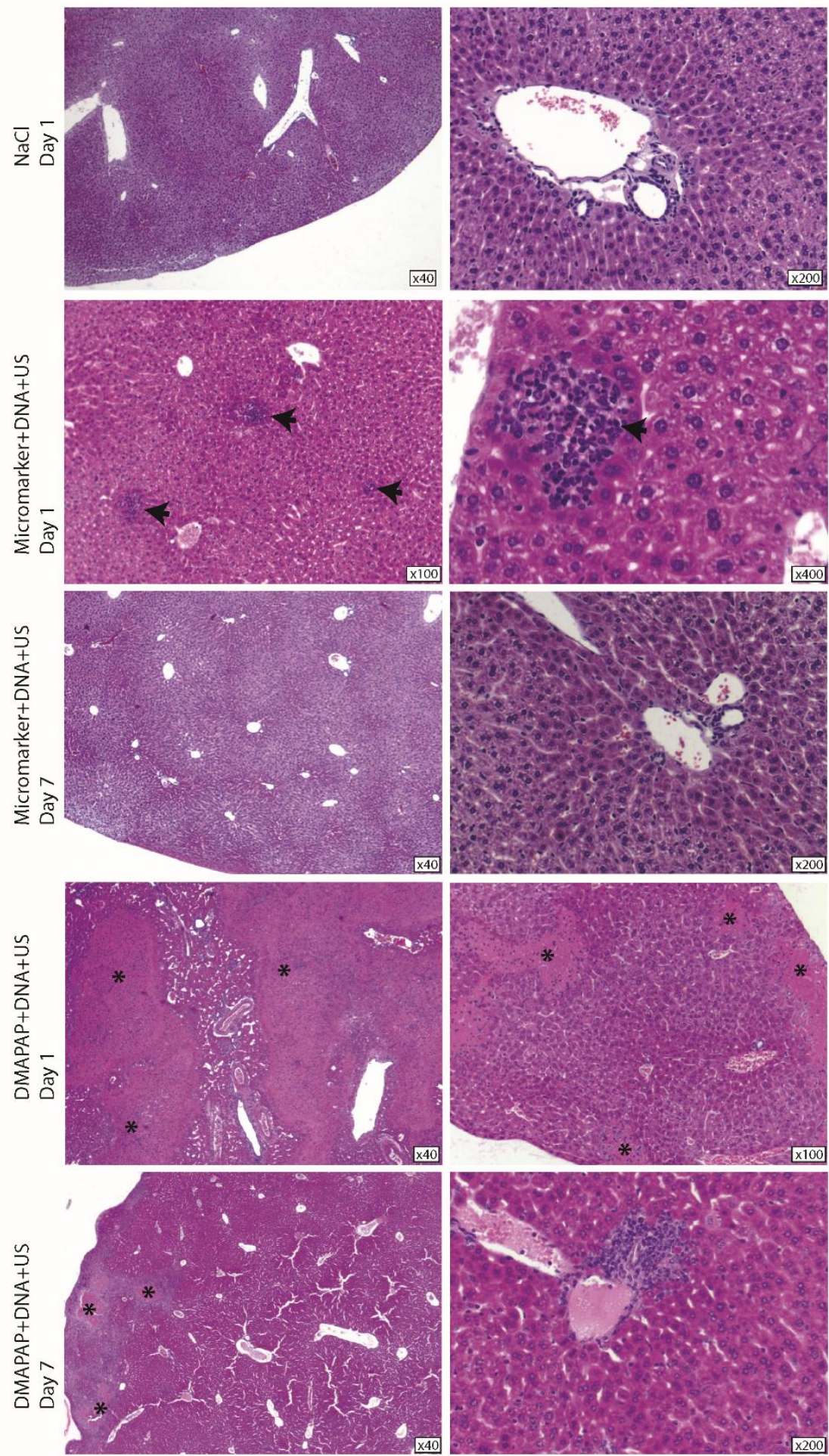

Figure 7: Histological examinations of liver sections. Histological analyses were performed on liver sections from mice tail-vein injected with pDNA and MB followed by US exposure using optimal conditions (930 kPa; $100 \mathrm{~Hz}$ PRF; DC 20\%; 6000 cycles). Arrows indicate inflammatory responses and stars indicate necrosis areas. 
At the end of the time course study, immunohistochemistry studies were performed to determine which types of cells were transfected when sonoporation was conducted either with MicroMarker ${ }^{\mathrm{TM}}$ or DMAPAP MB. We ought to evaluate the proportion of hepatocytes versus vascular endothelial cells that were transfected under those two conditions. As shown by the representative images, hepatocytes were much more transfected than endothelial cells following sonoporation made with DMAPAP MB (Figure 8). By contrast, the co-injection of pFAR4-LUC with MicroMarker ${ }^{\mathrm{TM}}$ led to a higher number of luciferase-expressing endothelial cells, as proven by the colocalization of antiluciferase and anti-CD31 antibodies. 


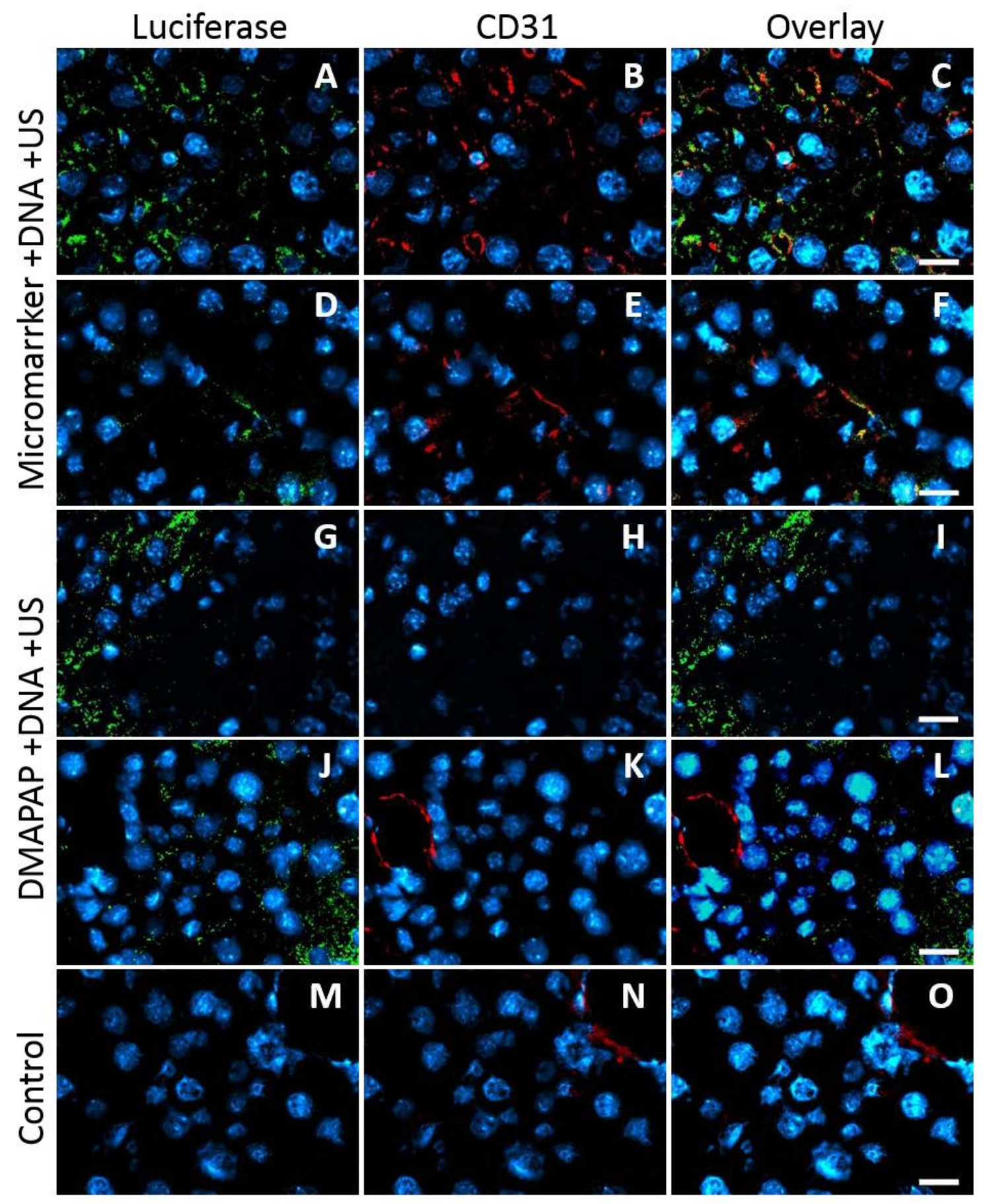

Figure 8: Assessment of transfected cell type by immunohistochemistry. Mice were tail vein injected with pFAR-LUC complexed with DMAPAP MB or co-injected with Micromarker ${ }^{\mathrm{TM}}$ followed by US exposure using optimal acoustic parameters. Liver sections from those treated mice and from non-treated control mice were processed for immunostaining. Luciferase expression was revealed with anti-luciferase antibody (green) immunolabelling; endothelial cells were identified by immunolabelling of CD31 marker (red). Cell nuclei were labelled with DAPI (blue). Scale bar: 100 $\mu \mathrm{m}$. 


\section{Discussion}

In this study, we developed cationic liposomal based MB based on DMAPAP cationic lipids, previously shown to be efficient for gene transfection when used as lipoplexes (pDNA/liposomes complexes). Liposomes made with this cationic lipid were able to interact with pDNA, protecting it from nuclease degradation, thus improving cellular uptake [31,32].

For an efficient ultrasound and MB-associated gene delivery, it is crucial to deliver sufficient pDNA at the sonoporation site. This can be achieved by loading pDNA on MB surface via direct interaction of either pDNA or pDNA complexed with cationic polymers or liposomes. Since different studies have reported that endocytosis could be also implicated in the sonoporation mechanism in addition to MB destruction [28,33,34], gas MB with DMAPAP branched cationic lipids could thereby be of interest. The DMAPAP cationic lipid allowed to produce MB exhibiting acoustic features. Cationic liposomal bubbles reported so far by other groups were usually comprised of neutral and cationic lipids. By contrast, our MB formulation was solely composed of the DMAPAP cationic lipids and of PEG moieties. The optimal proportion of PEG chains to mask positive charges without impairing the capacity of $\mathrm{MB}$ to form electrostatic interactions with pDNA was determined. The MB surface modifications induced by the MB-pDNA interaction did not alter the MB acoustic properties.

For the US energy generated, a mixture of both oscillation and destruction of DMAPAP MB has been found to occur as observed in our in vitro study. In particular, MB destruction was mainly obtained at higher acoustic pressure used during in vivo experiments. Therefore, both oscillations and destruction of MB are likely responsible for transfection obtained. For all tested acoustic pressures, using DC above $20 \%$ was not beneficial for gene transfer. Acute toxicity was also induced when the acoustic pressure was increased up to $1125 \mathrm{kPa}$.

Long term liver reporter gene expression was obtained with both neutral MicroMarker ${ }^{\mathrm{TM}}$ and positively charged microbubbles. However, a stable expression over 6 months at a level of $5 \times 10^{4}$ $\mathrm{ph} / \mathrm{s} / \mathrm{cm}^{2} / \mathrm{sr}$ could only be obtained by pDNA association with positively charged microbubbles. Thus, these newly designed cationic microbubbles associated with the small pFAR4 miniplasmid allowed to increase local pDNA concentration in the sonicated area, resulting in a higher plasmid copy number in the liver and a more stable expression. A long lasting gene expression up to 4 months has already been observed in sonoporated tendons using MicroMarker ${ }^{\mathrm{TM}} \mathrm{MB}$. In that study, the episomal form of pDNA was found to be responsible for this expression [7]. Here, it could be the case but DNA integration cannot be excluded even though this event is very rare.

Long term transgene expression is necessary for gene therapy, in order to avoid treatment repetition. Recent progresses in biotechnology resulted in the emergence of pDNA designed with either DNA 
transposons Sleeping Beauty [35], PiggyBac [36] or integrases such as $\phi$ C31 [37,38], which mediate transgene integration into host genomes and prolonged transgene expression. Nevertheless, DNA transposons still display the drawback of generating an integration profile which is not site-specific, potentially leading to side genotoxicity caused by insertional oncogenesis. In our study, we showed that a long term transgene expression could be obtained using pFAR4 miniplasmids. The advantages of these miniplasmids have been proven in vivo upon hydrodynamic injection thanks to their reduced size, nontoxic and non-immunogenic side effects [22,23]. These features may play a significant role in gene transfer efficiency by sonoporation.

In particular, the other noticeable point comes from the search of cells which have been transfected following liver sonoporation. Knowing the type of transfected cells is particularly important to select the appropriate application of the US protocol. Our immunohistochemistry analyses revealed that with cationic MB, hepatocytes are majorly transfected whilst endothelial cells were also transfected with neutral MB. Such identification had never been reported in previous studies. Hepatocytes surface can be reached from the space of Disse which is directly accessible to liver sinusoidal endothelia via fenestrae. These fenestrae contain pores that play a role for anatomical targeting. Unfortunately, the small size of those pores limits the anatomical targeting of gene delivery systems. In most cases, endothelial cells lining the vessel are transfected when the extravasation is inefficient. Opening the fenestrae of liver sinusoids is one of the consequences of hydrodynamic injection that allows an efficient hepatocytes gene transfer. During sonoporation, MB oscillations are also supposed to act on the endothelium and improve the extravasation through pores opening. When pDNA miniplasmids are compacted by cationic MB, our results show that the effectiveness of plasmid passage through the pores is improved, thus leading to a higher hepatocyte transfection. By contrast, when co-injected with neutral MB such as Micromarker ${ }^{\mathrm{TM}}$, transfection was mostly restricted to vessel endothelial cells. This study represents a first step towards using cationic MB and US for in vivo gene transfer in liver, which will require improvements for an increased efficiency.. Amongst published reports related to liver gene delivery by US and microbubbles, our study could be compared to those made by Song et al. [11,39] and Anderson et al., [10]. The injection mode was found to be crucial to get efficient gene delivery in the liver. Here, we have performed a tail vein injection which is more convenient and less invasive than intra-hepatic injection [11] or than the injection into the left ventricle of the heart [10] followed by ultrasound application in the liver. Our MB formulation was clearly stable enough; since MB could be detected in the liver by B-mode imaging (Figure 4). This image guidance was also of great help to finely adjust the mode of injection and the ultrasound parameters. 


\section{Conclusion}

The long-term expression obtained during this work can be likely attributed to the straightforward and reproducible preparation of MB formation using the DMAPAP lipid, to the small size of the pFAR miniplasmid, and to their oscillation properties leading to hepatocyte transfection under optimised ultrasound parameters. Nevertheless, there is still room for improvement to enhance the US-based gene transfer efficiency obtained with our new formulation.

\section{Acknowledgements}

This work was funded by the French National Agency for Research (ANR Blanc-MEDDU). Our acknowledgement to different platforms: 1) Animal Platform, CRP2 - UMS 3612 CNRS - US25 Inserm-IRD - Faculté de Pharmacie de Paris, Université Paris Descartes, Paris, France; 2) Optical imaging plateform LIOPA, Life imaging, PIV, Faculty of Pharmacy, Université Paris Descartes Univ., Paris, France. We are grateful to the histo-pathology service of Regional Hospital of Orléans (France) for their excellent expertise. 


\section{References}

[1] S.E. Raper, M. Grossman, D.J. Rader, J.G. Thoene, B.J. Clark, D.M. Kolansky, D.W. Muller, J.M. Wilson, Safety and feasibility of liver-directed ex vivo gene therapy for homozygous familial hypercholesterolemia., Ann. Surg. 223 (1996) 116-126. doi:10.1097/00000658199602000-00002.

[2] A.M. Salazar-Montes, L.D. Hernández-Ortega, M.S. Lucano-Landeros, J. ArmendarizBorunda, New gene therapy strategies for hepatic fibrosis, World J. Gastroenterol. 21 (2015) 3813-3825. doi:10.3748/wjg.v21.i13.3813.

[3] Y. Sakakima, S. Hayashi, Y. Yagi, A. Hayakawa, K. Tachibana, A. Nakao, Gene therapy for hepatocellular carcinoma using sonoporation enhanced by contrast agents, Cancer Gene Ther. 12 (2005) 884-889. doi:10.1038/sj.cgt.7700850.

[4] J.W. Castle, K.P. Kent, Y. Fan, K.D. Wallace, C.E.L. Davis, J.C. Roberts, M.E. Marino, K.E. Thomenius, H.W. Lim, E. Coles, M.H. Davidson, S.B. Feinstein, A. DeMaria, Therapeutic ultrasound: Increased HDL-Cholesterol following infusions of acoustic microspheres and apolipoprotein A-I plasmids, Atherosclerosis. 241 (2015) 92-99. doi:10.1016/j.atherosclerosis.2015.04.817.

[5] R. Suzuki, E. Namai, Y. Oda, N. Nishiie, S. Otake, R. Koshima, K. Hirata, Y. Taira, N. Utoguchi, Y. Negishi, S. Nakagawa, K. Maruyama, Cancer gene therapy by IL-12 gene delivery using liposomal bubbles and tumoral ultrasound exposure, J. Control. Release. 142 (2010) 245-250. doi:10.1016/j.jconre1.2009.10.027.

[6] A. Delalande, M. Postema, N. Mignet, P. Midoux, C. Pichon, Ultrasound and microbubbleassisted gene delivery: recent advances and ongoing challenges, Ther. Deliv. 3 (2012) 11991215. doi:10.4155/tde.12.100.

[7] A. Delalande, A. Bouakaz, G. Renault, F. Tabareau, S. Kotopoulis, P. Midoux, B. Arbeille, R. Uzbekov, S. Chakravarti, M. Postema, C. Pichon, Ultrasound and microbubble-assisted gene delivery in Achilles tendons: Long lasting gene expression and restoration of fibromodulin $\mathrm{KO}$ phenotype, J. Control. Release. 156 (2011) 223-230. doi:10.1016/j.jconrel.2011.08.020.

[8] G. Shapiro, A.W. Wong, M. Bez, F. Yang, S. Tam, L. Even, D. Sheyn, S. Ben-David, W. Tawackoli, G. Pelled, K.W. Ferrara, D. Gazit, Multiparameter evaluation of in vivo gene delivery using ultrasound-guided, microbubble-enhanced sonoporation, J. Control. Release. 223 (2016) 157-164. doi:10.1016/j.jconrel.2015.12.001. 
[9] C.H. Miao, A.A. Brayman, K.R. Loeb, P. Ye, L. Zhou, P. Mourad, L.A. Crum, Ultrasound enhances gene delivery of human factor IX plasmid., Hum. Gene Ther. 16 (2005) 893-905. doi:10.1089/hum.2005.16.ft-85.

[10] C.D. Anderson, S. Moisyadi, A. Avelar, C.B. Walton, R. V Shohet, Ultrasound targeted hepatic delivery of Factor IX in hemophiliac mice, Gene Ther. (2016) 1-47. doi:10.1038/gt.2016.23.

[11] S. Song, M. Noble, S. Sun, L. Chen, A.A. Brayman, C.H. Miao, Efficient microbubble- and ultrasound-mediated plasmid DNA delivery into a specific rat liver lobe via a targeted injection and acoustic exposure using a novel ultrasound system, Mol. Pharm. 9 (2012) 21872196. doi:10.1021/mp300037t.

[12] D. Yang, Y.-H. Gao, K.-B. Tan, Z.-X. Zuo, W.-X. Yang, X. Hua, P.-J. Li, Y. Zhang, G. Wang, Inhibition of hepatic fibrosis with artificial microRNA using ultrasound and cationic liposomebearing microbubbles., Gene Ther. 20 (2013) 1140-8. doi:10.1038/gt.2013.41.

[13] M.L. De Temmerman, H. Dewitte, R.E. Vandenbroucke, B. Lucas, C. Libert, J. Demeester, S.C. De Smedt, I. Lentacker, J. Rejman, MRNA-Lipoplex loaded microbubble contrast agents for ultrasound-assisted transfection of dendritic cells, Biomaterials. 32 (2011) 9128-9135. doi:10.1016/j.biomaterials.2011.08.024.

[14] K. Anwer, G. Kao, B. Proctor, I. Anscombe, V. Florack, R. Earls, E. Wilson, T. McCreery, E. Unger, A. Rolland, S.M. Sullivan, Ultrasound enhancement of cationic lipid-mediated gene transfer to primary tumors following systemic administration, Gene Ther. 7 (2000) 1833-1839. doi:10.1038/sj.gt.3301302.

[15] J.P. Christiansen, B.A. French, A.L. Klibanov, S. Kaul, J.R. Lindner, Targeted tissue transfection with ultrasound destruction of plasmid-bearing cationic microbubbles, Ultrasound Med. Biol. 29 (2003) 1759-1767. doi:10.1016/S0301-5629(03)00976-1.

[16] S. Hayashi, M. Mizuno, J. Yoshida, A. Nakao, Effect of sonoporation on cationic liposomemediated IFNbeta gene therapy for metastatic hepatic tumors of murine colon cancer, Cancer Gene Ther. 16 (2009) 638-643. doi:cgt20081 [pii]\r10.1038/cgt.2008.1.

[17] J.L. Tlaxca, C.R. Anderson, A.L. Klibanov, B. Lowrey, J.A. Hossack, J.S. Alexander, M.B. Lawrence, J.J. Rychak, Analysis of in vitro transfection by sonoporation using cationic and neutral microbubbles, Ultrasound Med. Biol. 36 (2010) 1907-1918. doi:10.1016/j.ultrasmedbio.2010.05.014. 
[18] M. Vannan, T. McCreery, P. Li, Z. Han, E. Unger, B. Kuersten, E. Nabel, S. Rajagopalan, Ultrasound-mediated transfection of canine myocardium by intravenous administration of cationic microbubble-linked plasmid DNA, J. Am. Soc. Echocardiogr. 15 (2002) 214-218. doi:10.1067/mje.2002.119913.

[19] C.H. Fan, C.Y. Ting, C.Y. Lin, H.L. Chan, Y.C. Chang, Y.Y. Chen, H.L. Liu, C.K. Yeh, Noninvasive, Targeted, and Non-Viral Ultrasound-Mediated GDNF-Plasmid Delivery for Treatment of Parkinson's Disease, Sci. Rep. 6 (2016) 19579. doi:10.1038/srep19579.

[20] L.E. Gracey Maniar, J.M. Maniar, Z.-Y. Chen, J. Lu, A.Z. Fire, M.A. Kay, Minicircle DNA vectors achieve sustained expression reflected by active chromatin and transcriptional level, Mol. Ther. 21 (2013) 131-8. doi:10.1038/mt.2012.244.

[21] E. Riu, Z. Chen, H. Xu, C. He, M.A. Kay, Histone Modifications are Associated with the Persistence or Silencing of Vector-mediated Transgene Expression, Gene Ther. 15 (2007) 1348-55. doi:10.1038/sj.mt.6300177.

[22] Z.Y. Chen, C.Y. He, A. Ehrhardt, M.A. Kay, Minicircle DNA vectors devoid of bacterial DNA result in persistent and high-level transgene expression in vivo, Mol. Ther. 8 (2003) 495-500. doi:10.1016/S1525-0016(03)00168-0.

[23] M. Quiviger, a Arfi, D. Mansard, L. Delacotte, M. Pastor, D. Scherman, C. Marie, High and prolonged sulfamidase secretion by the liver of MPS-IIIA mice following hydrodynamic tail vein delivery of antibiotic-free pFAR4 plasmid vector., Gene Ther. (2014) 1-7. doi:10.1038/gt.2014.75.

[24] G. Byk, D. Scherman, B. Schwartz, C. Dubertret, Lipopolyamines as transfection agents and pharmaceutical uses thereof, US Pat. 6,171,612. 1 (2001).

[25] B. Thompson, N. Mignet, H. Hofland, D. Lamons, J. Seguin, C. Nicolazzi, N. de la Figuera, R.L. Kuen, X.Y. Meng, D. Scherman, M. Bessodes, Neutral postgrafted colloidal particles for gene delivery., Bioconjug. Chem. 16 (2005) 608-14. doi:10.1021/bc040244z.

[26] S. Manta, A. Delalande, M. Bessodes, M.F. Bureau, D. Scherman, C. Pichon, N. Mignet, Characterization of Positively Charged Lipid Shell Microbubbles with Tunable Resistive Pulse Sensing (TRPS) Method: A Technical Note, Ultrasound Med. Biol. 42 (2016) 624-630. doi:10.1016/j.ultrasmedbio.2015.10.010.

[27] C. Marie, G. Vandermeulen, M. Quiviger, M. Richard, V. Préat, D. Scherman, pFARs, plasmids free of antibiotic resistance markers, display high-level transgene expression in 
muscle, skin and tumour cells, J. Gene Med. 12 (2010) 323-332. doi:10.1002/jgm.1441.

[28] A. Delalande, C. Leduc, P. Midoux, M. Postema, C. Pichon, Efficient gene delivery by sonoporation is associated with microbubble entry into cells and the clathrin-dependent endocytosis pathway, Ultrasound Med. Biol. 41 (2015) 1913-1926. doi:10.1016/j.ultrasmedbio.2015.03.010.

[29] Chen CC, Borden MA. Ligand conjugation to bimodal poly(ethylene glycol) brush layers on microbubbles. Langmuir. 2010; 26: 13183-94.

\{30] Feshitan JA, Chen CC, Kwan JJ, Borden MA. Microbubble size isolation by differential centrifugation. J Colloid Interface Sci. 2009; 329: 316-24;

[31] C. Bloquel, C. Trollet, E. Pradines, J. Seguin, D. Scherman, M.F. Bureau, Optical imaging of luminescence for in vivo quantification of gene electrotransfer in mouse muscle and knee., BMC Biotechnol. 6 (2006) 16. doi:10.1186/1472-6750-6-16.

[32] M. Breton, J. Leblond, J. Seguin, P. Midoux, D. Scherman, J. Herscovici, C. Pichon, N. Mignet, Comparative gene transfer between cationic and thiourea lipoplexes, J. Gene Med. 12 (2010) 45-54. doi:10.1002/jgm.1417.

[33] B.D.M. Meijering, L.J.M. Juffermans, A. Van Wamel, R.H. Henning, I.S. Zuhorn, M. Emmer, A.M.G. Versteilen, W.J. Paulus, W.H. Van Gilst, K. Kooiman, N. De Jong, R.J.P. Musters, L.E. Deelman, O. Kamp, Ultrasound and microbubble-targeted delivery of macromolecules is regulated by induction of endocytosis and pore formation, Circ. Res. 104 (2009) 679-687. doi:10.1161/CIRCRES AHA.108.183806.

[34] M. Derieppe, K. Rojek, J.-M. Escoffre, B.D. de Senneville, C. Moonen, C. Bos, Recruitment of endocytosis in sonopermeabilization-mediated drug delivery: a real-time study., Phys. Biol. 12 (2015) 46010. doi:10.1088/1478-3975/12/4/046010.

[35] L. Mates, M.K. Chuah, E. Belay, B. Jerchow, N. Manoj, A. Acosta-Sanchez, D.P. Grzela, A. Schmitt, K. Becker, J. Matrai, L. Ma, E. Samara-Kuko, C. Gysemans, D. Pryputniewicz, C. Miskey, B. Fletcher, T. VandenDriessche, Z. Ivics, Z. Izsvak, Molecular evolution of a novel hyperactive Sleeping Beauty transposase enables robust stable gene transfer in vertebrates, Nat. Genet. 41 (2009) 753-761. doi:10.1038/ng.343.

[36] M. Di Matteo, E. Samara-Kuko, N.J. Ward, S.N. Waddingon, J.H. McVey, M.K.L. Chuah, T. VandenDriessche, S.N. Waddington, J.H. McVey, M.K.L. Chuah, T. VandenDriessche, Hyperactive PiggyBac Transposons for Sustained and Robust Liver-targeted Gene Therapy, 
Mol. Ther. 22 (2014) 1614-1624. doi:10.1038/mt.2014.131.

[37] A. Keravala, S. Lee, B. Thyagarajan, E.C. Olivares, V.E. Gabrovsky, L.E. Woodard, M.P. Calos, Mutational derivatives of PhiC31 integrase with increased efficiency and specificity., Mol. Ther. 17 (2009) 112-120. doi:10.1038/mt.2008.241.

[38] A. Keravala, C.L. Chavez, G. Hu, L.E. Woodard, P.E. Monahan, M.P. Calos, Long-term phenotypic correction in factor IX knockout mice by using $\Phi C 31$ integrase-mediated gene therapy., Gene Ther. 18 (2011) 842-8. doi:10.1038/gt.2011.31.

[39] S. Song, Z. Shen, L. Chen, A.A. Brayman, C.H. Miao, Explorations of high-intensity therapeutic ultrasound and microbubble-mediated gene delivery in mouse liver., Gene Ther. 18 (2011) 1006-1014. doi:10.1038/gt.2011.34. 
Graphical abstract

Cationic microbubbles for imaging and efficient gene delivery in liver

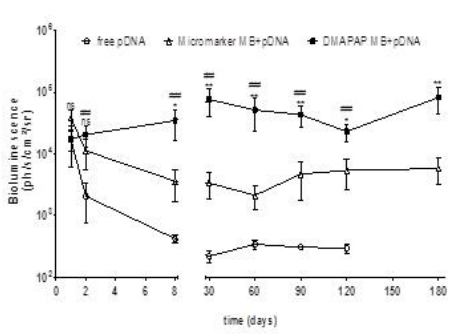

Kinetic of transgene expression

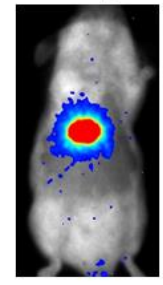

Bioluminescence

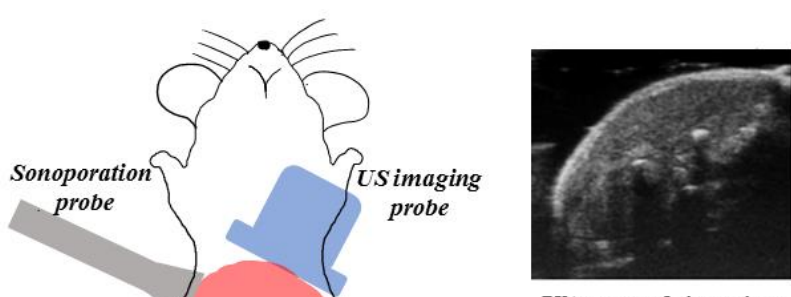

Ultrasound imaging

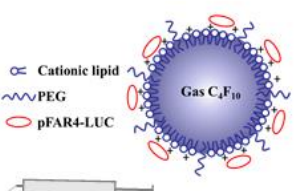

Cationic microbubbles bearing pFAR4-LUC administration 